\title{
Optimal Power Flow Problem Solution Incorporating FACTS Devices Using PSO Algorithm

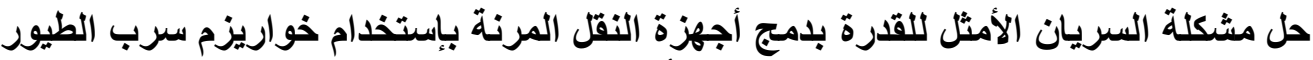

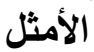 \\ R. A. Amer* , G. A. Morsy ${ }^{*}$ and Ekramy Saad** \\ "Department of Electrical Engineering, Faculty of Engineering, Minoufiya University, Shebin El-Kom, Egypt \\ **Egyptian Electricity Transmission Co., Alex. Zone, Egypt
}

\begin{abstract}
:
This paper presents an efficient and reliable evolutionary-based approach to solve the optimal power flow (OPF) problem. To search the optimal setting of control variables for the OPF, which is formulated as a nonlinear constrained objective optimization problem with both equality and inequality constraints, particle swarm optimization (PSO) algorithm is used. The standard IEEE 30-bus power system is studied to illustrate how the proposed method has an efficient role. The objectives are minimizing the total fuel cost, system power loss, installation cost of FACTS and voltage profile improvement. Two different types of FACTS devices are incorporated with the test system, SVC and UPFC, to achieve the objective functions under certain constraints. Furthermore, the proposed method is used to determine the optimal location of FACTS controller. The results show the effectiveness of UPFC with optimal settings over the SVC under the same conditions. Also, the results illustrate the importance of determination of the best location of FACTS devices.

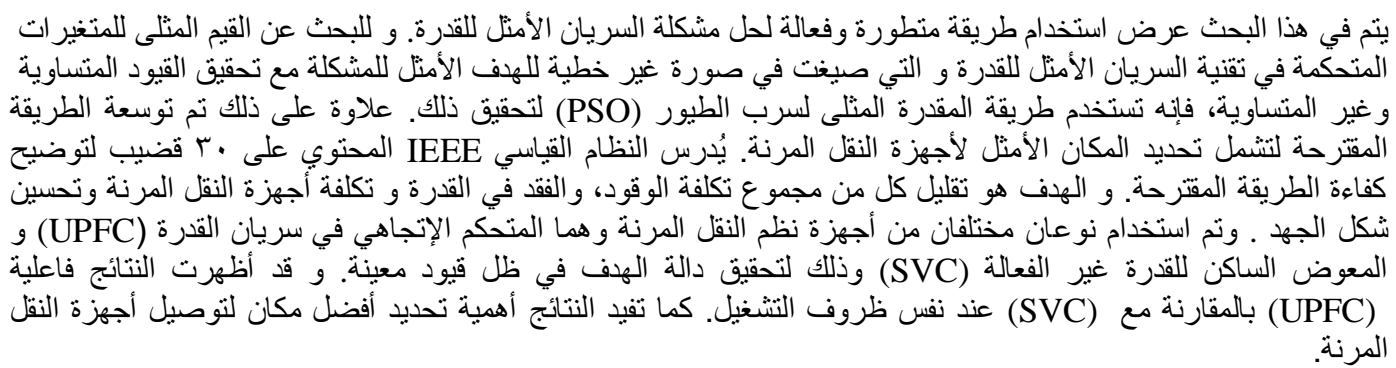

Key words-optimal power flow, particle swarm optimization, SVC and UPFC.

\section{INTRODUCTION}

The electrical energy demand increases continuously from time to time. This increase should be monitored or observed because few problems could appear with the power flows through the existing electric transmission networks. If this situation fails to be controlled, some lines located on the particular paths might become overloaded. Due to the overloaded conditions, the transmission lines will have to be driven close to or even beyond their transfer capacities. Building a new transmission line will not be the most suitable way to solve the problems; one possible solution to improve the system operation was the use of Flexible AC Transmission Systems (FACTS) technologies. It opens up new opportunities for controlling the power, decreasing the losses and enhancing the unstable capacity of existing transmission lines. However, not all transmission system can be provided by FACTS devices and it is important to select the type of devices in order to achieve the purpose [1]. FACTS devices can direct the active and reactive power to control voltagemagnitude control simultaneously, because of their adaptability and fast control characteristics. With the aid of FACTS technology, namely SVC, STATCOM, SSSC and UPFC etc., the bus voltages, line impedances and phase angles in the power system can be controlled quickly and flexibly [2].

Optimal power flow (OPF) is a nonlinear programming problem (NLP) which is used to minimize a desired objective function subject to certain system constraints by determining the optimal control parameter settings. Modern methods to solve 
OPF must be adjusted in order to satisfy the new challenges of the power industry coming from market and technological transformations. In fact, the development of competitive electricity markets has had an important impact on classical analysis tools. Broadly speaking, from steady-state network simulation point of view, OPF optimization methods can be separated into two major groups [3]:

- Group A: The calculation core of these models corresponds to a classic power flow algorithm, which is used by an external optimization process in an iterative way.

- Group B: The OPF problem is modeled as a global optimization problem, where control and state variables are optimized simultaneously. A set of constraints represent the steady-state operation of the system.

Several conventional techniques like nonlinear programming (NLP), quadratic programming, mixed integer programming and Newton techniques are used to obtain the solution for optimal power flow problems. The limitations of these methods lead to the development of evolutionary computing techniques like genetic algorithm (GA), simulated annealing (SA), particle swarm optimization (PSO), tabu search (TS), Differential Evolution algorithm (DE) and many more. These algorithms can solve complex optimization problems which are non-linear, discontinuous, non-differentiable and multidimensional [4].

The authors of [1] have presented the application of evolutionary computation technique for loss minimization and UPFC installation cost. Evolutionary Programming (EP) and Artificial Immune System (AIS) methods are applied for the minimization of real power loss as the objective function. Simulation is carried out on the IEEE 30bus test system. In [2], UPFC is modeled as combination of a TCSC in series with the line and SVC connected in shunt across the corresponding buses. The proposed technique was implemented and tested using IEEE 14 \& 30 bus systems. In Ref. [3], the authors have presented a formulation of the Optimal Power Flow problem with an explicit modeling of Static Var Compensator (SVC) and Unified Power Flow Controller (UPFC) devices. Practical applications to real longitudinal systems are discussed, where FACTS location and UPFC based interconnection are studied. The authors of [4] determine the optimal location and control parameters settings of Unified Power Flow Controller (UPFC) with regard to power loss minimization. Differential Evolution Algorithm (DE) and Genetic Algorithm (GA) are employed to solve optimal power flow problems. The authors of [5] have presented the best location for the UPFC to optimize the total fuel cost, power losses and the system loadability as objective functions while the investment cost of UPFC is minimized. Computer simulations were done for IEEE 14, 30, and 118- bus systems.

In [6], PSO technique is proposed to optimize the sizing of FACTS devices in order to minimize the transmission loss in the system. The SVC is chosen as the device for compensation and modeled as a reactive source added at the bus. Placement of SVC is done empirically as the pilot study.

Ref. [7] made an attempt to find the optimal location and size of SVC device for decreasing voltage stability index, power loss, voltage deviation, the cost of generating unit and cost of SVC device using PSO and GA for different loading condition. Simulations were performed on IEEE 14, 30 and 57 bus systems. This paper presents PSO technique for minimizing each of the total fuel cost, system power losses, installation cost of FACTS and voltage profile improvement. This technique is applied in IEEE 30bus system incorporating each of UPFC and SVC. PSO was adopted to optimize the UPFC and the SVC sizing to be installed in power transmission network. The optimal placement of FACTS (SVC and UPFC) devices are determined using PSO technique.

\section{FACTS DEVICES}

Referring to IEEE, FACTS definition is as "a power electronic based system and other static equipment that provide control of one or more $\mathrm{AC}$ transmission system parameters to enhance controllability and increase power transfer capability". FACTS devices are proven to be effective in power grids in welldeveloped countries such as USA, Canada and Sweden. This technology can boost power transfer capability by $20-30 \%$ by increasing the flexibility of the systems. It can also increase the loadability, where additional loads can be added in the system without addition of new transmission and generating facilities [8]. FACTS have some relative merits and they are summarized as follow [2]:

1- Balancing of load flows

This enables the load flow on parallel circuits and optimizing different voltage levels, with a minimum of power wheeling, the best possible utilization of the lines, and overall system losses can be minimized at the same time.

2- Increasing of first swing stability, power oscillation damping, and voltage stability

This can maximize the system availability as well as power transmission capability over either existing or new lines. Thus, more power can be transmitted over fewer lines, with a saving of money as well as of environmental impact of the transmission link.

3- Mitigation of sub synchronous resonance risk Sub synchronous resonance (SSR) is a phenomenon which can be associated with series compensation under certain adverse conditions. The elimination of 
the risk of SSR even for the most onerous conditions means that the series compensation concept can be utilized in situations where it would otherwise not have been undertaken, there by widening the usefulness of series compensation.

\section{4- Power system interconnection}

Interconnecting of power systems is becoming increasingly widespread as part of power exchange between countries as well as regions within countries in many parts of the world. Such are found in the Nordic countries, Argentina, and Brazil.

In this paper, two typical FACTS devices have been selected: SVC (Static Var Compensator) and UPFC (Unified Power Flow Controller).

\subsection{Basic Concept and Modeling of SVC:}

The SVC consists of a group of shunt-connected capacitors and reactors banks with fast control action by means of thyristor switching circuits. For operating, the SVC can be considered as a variable shunt reactance that adjusts itself automatically according to the system operative conditions. According to nature of the equivalent SVC's reactance, i.e. capacitive or inductive, the SVC draws either capacitive or inductive current from the network. As this equivalent reactance of the connected SVC is suitably controlled, it allows the voltage magnitude to regulate at the connection point of SVC. The most popular configuration for continuously controlled SVC is the combination of either fix capacitor and thyristor controlled reactor or thyristor switched capacitor and thyristor controlled reactor. For steady-stale analysis, both the configurations can be modeled along similar lines [9]. The SVC can inject or absorb its reactive power $\left(\mathrm{Q}_{\mathrm{svC}}\right)$ at a chosen bus. It injects reactive power into the system $\mathrm{Q}_{\mathrm{SvC}}<0$ and absorbs reactive power from the system if $\mathrm{Q}_{\mathrm{SvC}}>0$ [10]. As an important component for voltage control, it is usually installed at the receiving node of the transmission lines. In Fig. 1 , the SVC has been considered as a shunt branch with a compensated reactive power $\mathrm{Q}_{\mathrm{svC}}$, set by available inductive and capacitive susceptances [11].

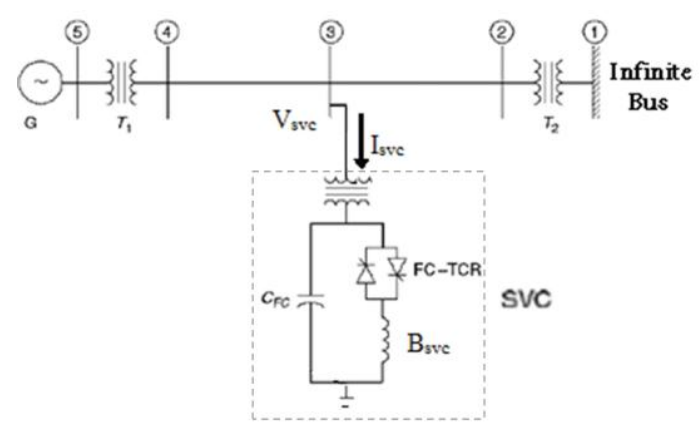

Fig.1 Circuit diagram of SVC connected to an infinite bus Referring to Fig. 1, the current drawn and reactive power injected by the SVC can be expressed as:
$\mathrm{I}_{\mathrm{SVC}}=\mathrm{JB}_{\mathrm{SVC}} * \mathrm{~V}$

(1)

$$
\mathrm{Q}_{\mathrm{SVC}}=-\mathrm{JB}_{\mathrm{SVC}} * \mathrm{~V}^{2}
$$

where $B_{\mathrm{svc}}, \mathrm{I}_{\mathrm{svc}}$ and $\mathrm{Q}_{\mathrm{svc}}$ are the susceptance, injected current and injected reactive power of SVC, respectively. The size of an SVC is expressed as an amount of reactive power supplied to a bus whose voltage is 1 p.u.

\subsection{Basic Concept and Modeling of UPFC}

The Unified Power Flow Controller (UPFC) concept was proposed by Gyugyi in 1991. The UPFC was devised for the real-time control and dynamic compensation of ac transmission systems, providing multifunctional flexibility required to solve many of the problems facing the power delivery industry [8].

The UPFC consists of two voltage source converters, as illustrated in Fig. 2. The two back-to-back converters, as labeled "Shunt Converter" and "Series Converter" in the figure are designed to be operated from a common DC link voltage supported by a DC storage capacitor [12].

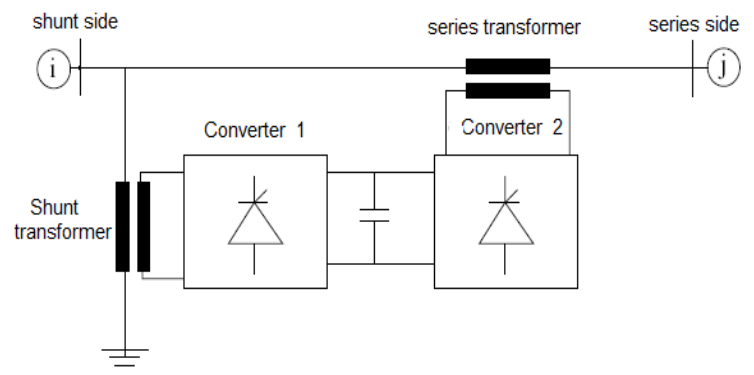

Fig. 2 Implementation of UPFC back-back voltage source converters

One converter is connected in shunt to the sending end node while the second converter is connected in series between the sending and receiving end nodes. The series converter performs the main function of the UPFC by injecting an AC voltage with controllable magnitude and phase angle in series with the transmission line. The UPFC cannot generate or absorb active power and as such the active power in the two converters must balance when active power loss is neglected. This is achieved via the DC link. The converters, however, may generate or absorb reactive power. The shunt converter can generate or absorb controllable reactive power and provide independent shunt reactive compensation for the line. UPFC can then regulate active and reactive power simultaneously. In principle, UPFC can perform voltage support, power flow control and dynamic stability improvement in one and the same device [8]. In practice, UPFC is the combination of STATCOM on the shunt side and SSSC on the series side. Therefore, the same UPFC steady-state model can be used to model and develop load flow analysis considering SSSC and STATCOM devices. The implementation FACTS devices, UPFC, SSSC and 
STATCOM into load flow solution required several modifications to the usual load flow algorithm. To take in account, the powers contributed by FACTS are included into power mismatches calculation, modification in elements of the Jacobian matrix due to the contributions of the voltage sources of the FACTS, change in the admittance matrix come from shunt and series impedance, this increase the complexity of programming [13]. Figure 3 shows the steady state model of the UPFC [14].

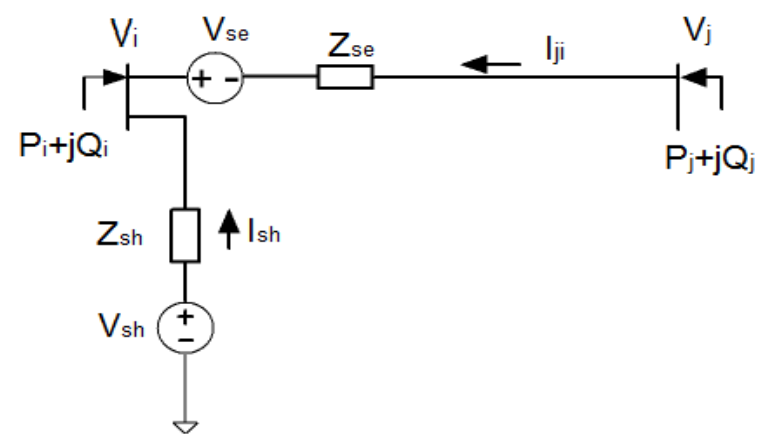

Fig. 3 The steady state model of the UPFC

The voltage sources $V_{s h}$ and $V_{s e}$ are controllable in both their magnitudes and phase angles. $R$ and $\gamma$ are the magnitude and phase angle of series voltage source respectively, operating within the following specified limits given by,

$0 \quad \leq r \leq r_{\max } \quad$ and $\quad 0 \leq \gamma \leq 2 \pi$

$V_{s e}$ should be defined as:

$\mathrm{V}_{\text {se }}$

(4)

$$
=
$$

The series element of UPFC can be represented by its Norton's equivalent circuit which comprises of a current source $I_{s e}$ parallel with admittance $Y_{s e}$ as shown in Fig. 3.a. The current $I_{s e}$ is equal to current $I_{j i}$.

where, $Y_{s e}$ includes the admittances of line $i-j$ and the series transformer of the UPFC and $I_{j i}$ is the current flowing in the transmission line from node $j$ to node $I$ as shown in Fig. 3.

$\mathrm{Y}_{\mathrm{se}}=1 / \mathrm{Z}_{\mathrm{se}}=\mathrm{g}_{\mathrm{se}}+\mathrm{jb} \mathrm{be}_{\mathrm{se}}$

(5)

$\mathrm{I}_{\mathrm{se}}=\mathrm{V}_{\mathrm{se}} \cdot \mathrm{Y}_{\mathrm{se}}$

(6)

where, $g_{s e}$ and $b_{s e}$ are the conductance and susceptance respectively.

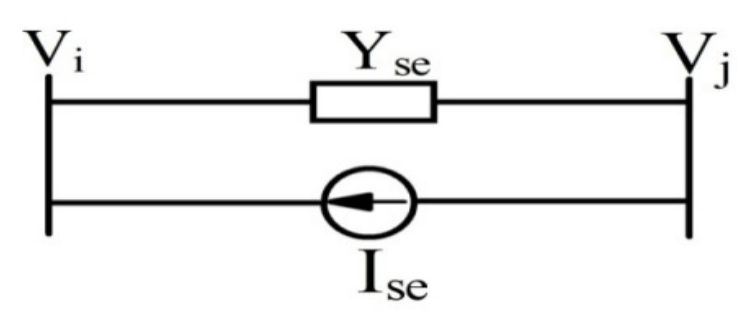

Fig. 3.a Norton's equivalent of UPFC series element

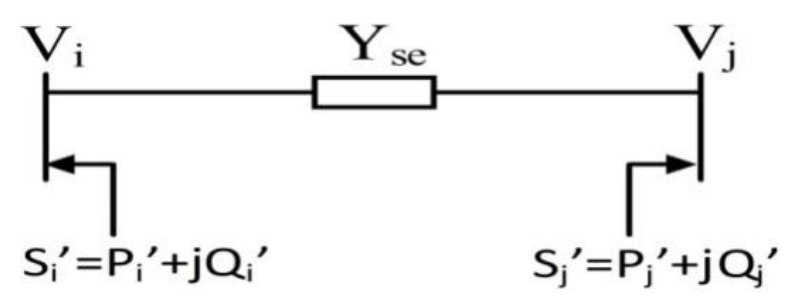

Fig. 3.b Power injection model of UPFC series element

The current source $\mathrm{I}_{\mathrm{se}}$ can be modeled by injection powers $S_{i}{ }^{\prime}$ and $S_{j}{ }^{\prime}$ at the buses $i$ and $j$ respectively as shown in the Fig. 3.b, where,

$\mathrm{S}_{\mathrm{i}}{ }^{\prime}=\mathrm{V}_{\mathrm{i}}\left(\mathrm{I}_{\mathrm{ji}}\right)^{*}=\mathrm{V}_{\mathrm{i}} \angle \delta_{\mathrm{i}}\left[\left(\mathrm{V}_{\mathrm{se}} \angle \theta_{\mathrm{se}}+\mathrm{V}_{\mathrm{j}} \angle \delta_{\mathrm{j}}-\mathrm{V}_{\mathrm{i}} \angle \delta_{\mathrm{i}}\right) \mathrm{Y}_{\mathrm{se}}\right]^{*}$

$\mathrm{S}_{\mathrm{j}}{ }^{\prime}=\mathrm{V}_{\mathrm{j}}\left(-\mathrm{I}_{\mathrm{ji}}\right)^{*}=\mathrm{V}_{\mathrm{j}} \angle \delta_{\mathrm{j}}\left[-\left(\mathrm{V}_{\mathrm{se}} \angle \theta_{\mathrm{se}}+\mathrm{V}_{\mathrm{j}} \angle \delta_{\mathrm{j}}-\mathrm{V}_{\mathrm{i}} \angle \delta_{\mathrm{i}}\right) \mathrm{Y}_{\mathrm{se}}\right]^{*}$

(8)

where, $V_{s e} \angle \theta_{s e}$ is the complex value of series injected voltage.

The active and reactive powers injected by series element at the buses $I$ and $j$ can be obtained from (7) and (8) as:

$\mathrm{P}_{\mathrm{i}}^{\prime}=\operatorname{Real}\left(\mathrm{S}_{\mathrm{i}}^{\prime}\right) \& \mathrm{Q}_{\mathrm{i}}^{\prime}=\operatorname{Imaj}\left(\mathrm{S}_{\mathrm{i}}^{\prime}\right)$

(9)

$\mathrm{P}_{\mathrm{j}}^{\prime}=\operatorname{Real}\left(\mathrm{S}_{\mathrm{j}}^{\prime}\right) \quad \& \mathrm{Q}_{\mathrm{j}}^{\prime}=\operatorname{Imaj}\left(\mathrm{S}_{\mathrm{j}}{ }^{\prime}\right)$

(10)

Also, the shunt element of UPFC can be represented by ac current source $I_{s h}$ parallel with admittance $Y_{s h}$ as shown in Fig. 4.a, where,

$\mathrm{Y}_{\mathrm{sh}}=1 / \mathrm{Z}_{\mathrm{sh}}=\mathrm{g}_{\mathrm{sh}}+\mathrm{jb} \mathrm{b}_{\mathrm{sh}}$

(11)

$\mathrm{I}_{\mathrm{sh}}=\mathrm{V}_{\mathrm{sh}} \mathrm{Y}_{\mathrm{sh}}$

(12)

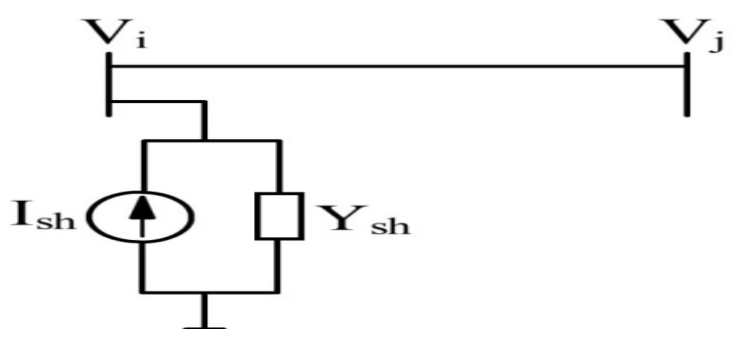

Fig. 4.a Norton's equivalent of shunt element 


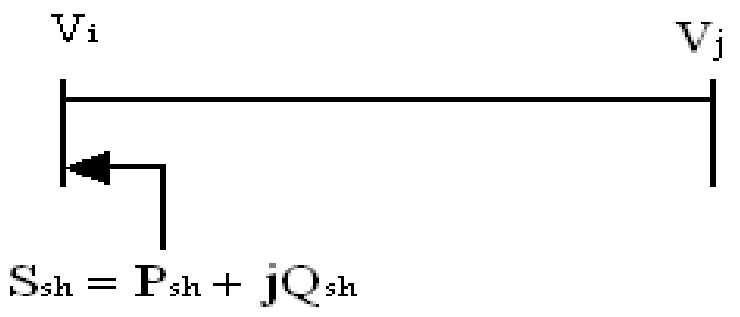

Fig. 4.b Power injection model of shunt element of UPFC The current source $I_{s h}$ can be modeled by injection power $S_{s h}$ at the bus $I$ as shown in the Fig. 4.b, where,

$\mathrm{S}_{\mathrm{sh}}=\mathrm{V}_{\mathrm{i}}\left(\mathrm{I}_{\mathrm{sh}}\right) *=\mathrm{V}_{\mathrm{i}} \angle \delta_{\mathrm{i}}\left[\left(\mathrm{V}_{\mathrm{sh}} \angle \theta_{\mathrm{sh}}-\mathrm{V}_{\mathrm{i}} \angle \delta_{\mathrm{i}}\right) \mathrm{Y}_{\mathrm{sh}}\right] *$

where, $V_{s h} \angle \theta_{s h}$ is the complex value of shunt voltage injected at bus $i$. The active and reactive powers injected by shunt element at the bus $I$ can be obtained from (11) as:

$\mathrm{P}_{\mathrm{sh}}=\quad \operatorname{Real}\left(\mathrm{S}_{\mathrm{sh}}\right) \quad \& \quad \mathrm{Q}_{\mathrm{sh}}=\quad \operatorname{Imaj}\left(\mathrm{S}_{\mathrm{sh}}\right)$ (14)

\section{PROBLEM FORMULATION}

The OPF problem is to optimize the steady state performance of a power system in terms of one objective function while satisfying several equality and inequality constraints. Now the OPF formulation has been modified with the variable parameters of the SVC and UPFC devices individually. Mathematically, it can be written as a nonlinear optimization problem as follows:

$\begin{array}{ll}\text { Minimize } & f(x) \\ \text { (15) } & \\ \text { Subject to: } & g(x)=0 \\ \text { (16) } & \end{array}$

$$
h(x)
$$$$
\leq
$$

where, $f(x)$ is the objective function, $\mathrm{g}(\mathrm{x})$ and $\mathrm{h}(\mathrm{x})$ are the set of equality and inequality constraints respectively and $x$ is the vector of control and state variables. The control variables are generator active and reactive power outputs, bus voltages and transformers tap-setting. The state variables are voltage and angle of load buses. Generally the problem can be formulated in the following.

\subsection{Objective Functions}

Several objectives will be studied in this paper, these objectives are minimizing of total fuel cost, FACTS installation cost minimization, total active power losses minimization and voltage profile improvement, as follows:

\section{A) Total Fuel Cost}

For optimal active power dispatch, the objective function $f$ is total generation cost, which represented by a quadratic polynomial expressed as follows:
$\operatorname{Min}$

$$
f_{1}=\sum_{i=1}^{N_{g}} a_{i}+b_{i} P_{g}+C_{i} P_{g}^{2}
$$

(18)

where, $N_{g}$ is the number of thermal units, $P_{g i}$ is the active power generation at unit $\mathrm{i}$ and $a_{i}, b_{i}$ and $c_{i}$ are the cost coefficients of the $i^{\text {th }}$ generator.

The standard IEEE 30-bus power system, which consists of six-generators located at buses 1, 2, 3, 4, 5 , and 6, 41 branches (lines) and four transformers in lines 9-13, 10-13, 8-12, and 28-27 as shown in Fig. 5 [16].

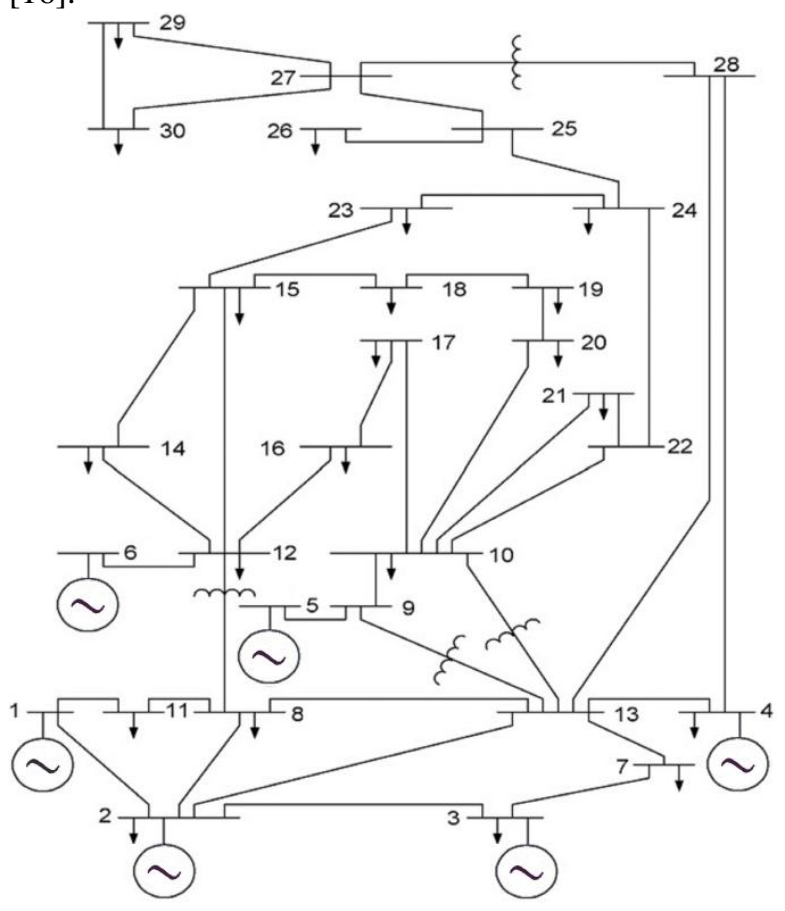

Fig. 5 The single line diagram of IEEE 30 bus test system

The values of generators cost coefficients are given in Table 1.

Table 1 Generators cost coefficients.

\begin{tabular}{|c|c|c|c|c|c|c|}
\hline \multirow{2}{*}{ Coefficients } & \multicolumn{7}{|c|}{ Generator } \\
\cline { 2 - 7 } & $\mathrm{G}_{1}$ & $\mathrm{G}_{2}$ & $\mathrm{G}_{3}$ & $\mathrm{G}_{4}$ & $\mathrm{G}_{5}$ & $\mathrm{G}_{6}$ \\
\hline $\mathrm{a}$ & 0.0 & 0.0 & 0.0 & 0.0 & 0.0 & 0.0 \\
\hline $\mathrm{b}$ & 200 & 175 & 100 & 325 & 300 & 300 \\
\hline $\mathrm{c}$ & 37.5 & 175 & 625 & 83.4 & 250 & 250 \\
\hline
\end{tabular}

b) Installation Cost of FACTS

The cost function of the SVC as in (Habur and Oleary, 2004) can be represented as [7]:

$\mathrm{C}_{\mathrm{SVC}}=0.0003 \mathrm{~S}^{2}-0.305 \mathrm{~S}+127.38$

$\$ / \mathrm{KVar}$

(19)

where,

$\mathrm{C}_{\mathrm{SVC}}=$ Cost of $\mathrm{SVC}$ in $\$ / \mathrm{KVar}$

$\mathrm{S}=$ Operating range of $\mathrm{SVC}$ in MVAR

$\mathrm{S}=\mathrm{Q}_{2}-\mathrm{Q}_{1}$

$\mathrm{Q}_{1}=\mathrm{MV}$ ar flow before placing FACTS device 
$\mathrm{Q}_{2}=\mathrm{MVar}$ flow after placing FACTS device

Based on the Siemens AG Database [5], the cost function for UPFC is developed as:

$C_{U P F C}=0.0003 S^{2}-0.2691 S+188.22 \$ / \mathrm{KVar}$

(20)

where $S$ is the operating range of the UPFC device in MVar.

The installation cost of FACTS devices must be unified into $\$ / \mathrm{hr}$. Normally, the FACTS devices will be in service for many years. However, only a part of its life time is employed to regulate the power flow. In this paper, ten years is applied to evaluate the cost function. Therefore the average values of the investment costs are calculated using the following equation:

$C_{1}(f)=\frac{C(f)}{8760 \times 10} \quad \$ / \mathrm{hr}$

(21)

where $C(f)$ is the total installation costs of FACTS devices in $\$$.

The cost functions for the SVC and UPFC are shown in Fig. 6.

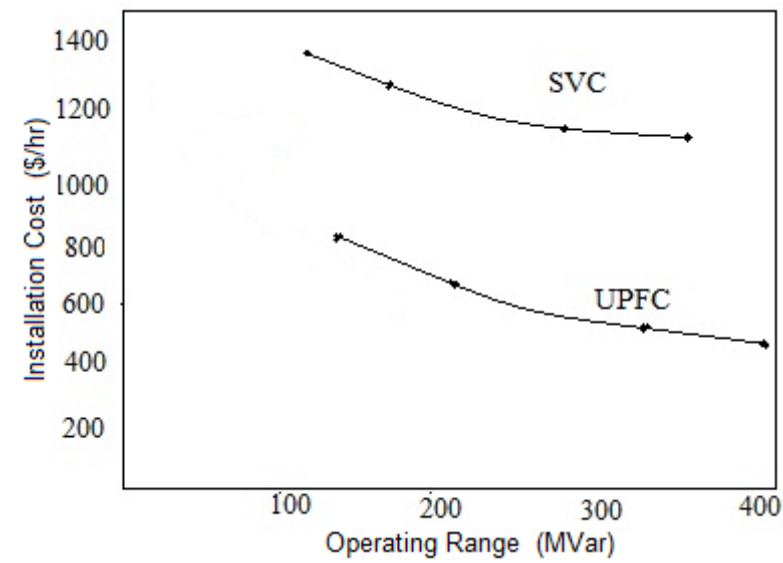

Fig. 6 The cost function for the SVC and UPFC

c) Active Power Loss

The third objective is minimizing the total active power loss in the transmission network, where it is a function of both buses voltage magnitude and buses voltage angle as follows [5]:

$$
\operatorname{Min} f_{3}=\sum_{k=i}^{n l} g_{k}\left[V_{i}^{2}+V_{j}^{2}-2 V_{i} V_{j} \cos \theta_{i j}\right]
$$

where $g_{k}$ is the conductance of branch between bus $i$ and bus $j, V_{i}$ and $V_{j}$ are the voltages at buses $i$ and $j$ and $\mathrm{nl}$ is the total number of transmission lines.

d) Voltage Profile Improvement

In such a power network, it is desirable to keep the voltage deviations between $\pm 5 \%$ to avoid voltage collapses during faulty conditions. In general, if the load requirements increase, the voltages at the corresponding buses may drop below 0.95 P.U. and consequently an additional voltage support is needed at that particular bus. Connecting the UPFC and SVC at suitable bus will minimize the voltage deviation and improve the voltage stability.

Minimizing the voltage deviation can express by the following equation:

Min

$$
f_{4}=\sum_{i=1}^{n p q}\left|V_{i}-V_{r e f}\right|
$$

\subsection{Constraints}

The equality constraints $g(x)$ are the power flow equations, expressed as follows:

$$
P_{g i}-P_{d i}=\sum_{j=1}^{N}|V i\|V j\| Y i j| \cos (\delta i-\delta j-\delta i j)
$$

$$
Q_{g i}-Q_{d i}=\sum_{j=1}^{N}|V i\|V j\| Y i j| \operatorname{Sin}(\delta i-\delta j-\delta i j)
$$

The inequality constraints $h(x)$ reflect the limits on physical devices in the power system as well as the limits created to ensure system security, such the limits on active and reactive generations, the bounds on the tap ratio $(\mathrm{t})$, the upper limit on the active power flow $\left(P_{i j}\right)$ of line $\mathrm{i}-\mathrm{j}$, the bounds in bus voltage magnitudes, the bounds in FACTS parameters and these can be expressed as follows:

$$
\begin{aligned}
& P_{g i}^{\min } \leq P_{g i} \leq P_{g i}^{\max }, Q_{g i}^{\min } \leq Q_{g i} \leq Q_{g i}^{\max } \\
& \boldsymbol{t}_{i j}^{\min } \leq \boldsymbol{t}_{i j} \leq \boldsymbol{t}_{i j}^{\max } \\
& \left|\boldsymbol{P}_{i j}\right| \leq \boldsymbol{P}_{i j}^{\max } \\
& V_{i}^{\min } \leq V_{i} \leq V_{i}^{\max } \\
& Q^{\min }<Q_{\text {FACTS }}<Q^{\max } \\
& 0 \leq \mathrm{r} \leq \mathrm{r}^{\max } \text { and } 0 \leq \gamma \leq 2 \pi
\end{aligned}
$$

\section{PARTICLE SWARM OPTIMIZATION (PSO)}

\subsection{PSO overview}

PSO algorithm originally is developed by Kennedy and Eberhart based on the social behaviors of animal swarms (e.g. bird blocks and fish schools). The PSO provides a population-based search procedure in which individuals called particles and changes their positions. The position of each particle is presented 
in $\mathrm{X}-\mathrm{Y}$ plane. Each particle moves to the new position using velocity according to its own experience called as $P_{\text {best }}$. $G_{\text {best }}$ is the overall best value obtained so far by any particle in the population. By time to time, the PSO consists of velocity changes of each particle towards its $P_{\text {best }}$ and $G_{\text {best }}$. Each particle tries to modify its current position and velocity according to the distance between its current position and $P_{\text {best }}$, and the current position and $G_{b e s t}$. After finding the best values the particle updates its velocity and position [6, 12]. The basic terms used in PSO technique are stated and defined in [15]. The particles are manipulated according to the following equations [15]:

$V_{j d}=w V_{j d}+c_{1} r_{1}\left(P_{j d}-X_{j d}\right)+c_{2} r_{2}\left(P_{g d}-X_{j d}\right)$

$X_{j d}=X_{j d}+V_{j d}$

where, $\mathrm{g}$ is the best particle among all particles, $\mathrm{c}_{1}$ and $c_{2}$ are positive constant and $r_{1}$ and $r_{2}$ are uniformly distributed numbers in $(0,1)$.

The inertia factor decreases linearly from about 0.9 to 0.4 during a run. In general, this factor is set according to the following equation:

$\mathrm{W}=\mathrm{W}_{\max }\left(\left(\mathrm{W}_{\max }-\mathrm{W}_{\min }\right) /\right.$ iter $\left._{\max }\right) \times$ iter

where, iter $_{\max }$ is the maximum number of iterations and iter is the current number of iterations.

\subsection{PSO implementation}

The proposed PSO based approach was implemented using Intel core i3 $1.0 \mathrm{GHz}$ processor with $4 \mathrm{~GB}$ of RAM in MATLAB 10.0. Initially, several runs have been done with different values of the PSO key parameters such as inertia weight and the maximum allowable velocity. Other parameters are selected as in Table 2.

Table 2 PSO parameters Values

\begin{tabular}{|c|c|}
\hline Parameters & Optimal Values \\
\hline Number of particles $(\mathrm{n})$ & 25 \\
\hline Iteration (iter) & 100 \\
\hline inertia weight $(\mathrm{w})$ & $0.9-0.4$ \\
\hline $\begin{array}{c}\text { Individual and Social acceleration } \\
\text { constant }\left(\mathrm{C}_{1} \& \mathrm{C}_{2}\right)\end{array}$ & 2 \\
\hline random numbers $\left(\mathrm{rand}_{1} \& \mathrm{rand}_{2}\right)$ & $0-1$ \\
\hline
\end{tabular}

\section{SIMULATION AND NUMERICAL RESULTS}

The proposed algorithm is implemented and tested on the studied system. The system total active power load is $189.2 \mathrm{MW}$ while the total reactive power load is 126.2 MVar. The base power is taken as 100 MVA. For the studies, the PV and slack bus voltages between 0.95 to 1.15 , The algorithms have been implemented using the MATLAB programming language, detailed analyses of the results are presented and discussed in this section.

Minimizing each of "total fuel cost", "installation cost of FACTS" and "total active power losses", also "improving the voltage profile" are the objectives which will be studied considering the SVC and UPFC devices. The proposed algorithm will be applied to determine the optimal location of FACTS devices and the optimal setting of control variables which satisfy the objectives functions.

\subsection{OPF using PSO considering SVC}

In this case, a SVC is considered in OPF calculation which embedded with the tested system. The proposed algorithm (PSO) will be used to determine the optimal location of SVC device to achieve the objectives functions. It is found that the optimal location for SVC at bus 8.

The variation of the total fuel cost is shown in Fig. 7. Referring to this figure, the total cost is optimized to 800.627 \$/hr.

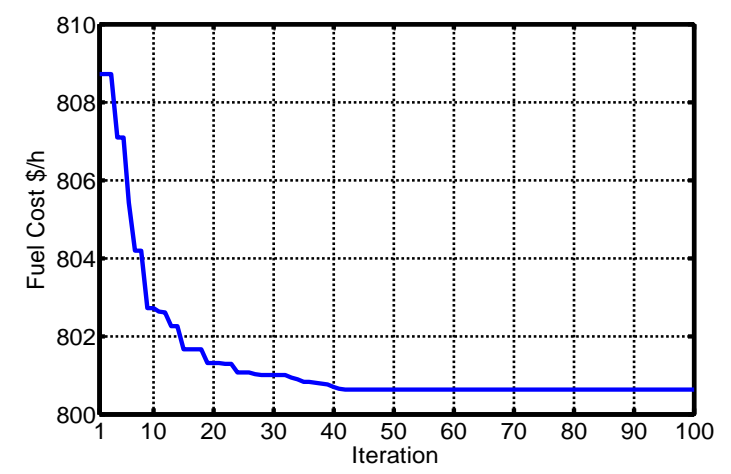

Fig. 7 The variation of fuel cost considering SVC

Fig. 8 shows the variation of active power losses, where the SVC located at bus 8 . Referring to this figure, the total power loss is optimized to $3.12 \mathrm{MW}$.

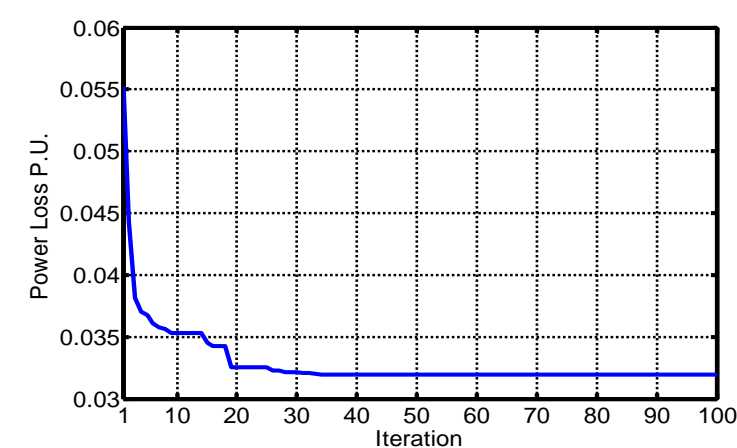

Fig. 8 The power loss variation considering SVC

For minimizing the summation of voltage deviation and the SVC is located at bus 8 , it is found that the variation of voltage deviation is minimized to 0.0275 . The system voltage profile considering SVC device and it is compared to that of the case without FACTS 
shown in Fig. 9. It is evident that the voltage profile is greatly improved when the SVC is considered.

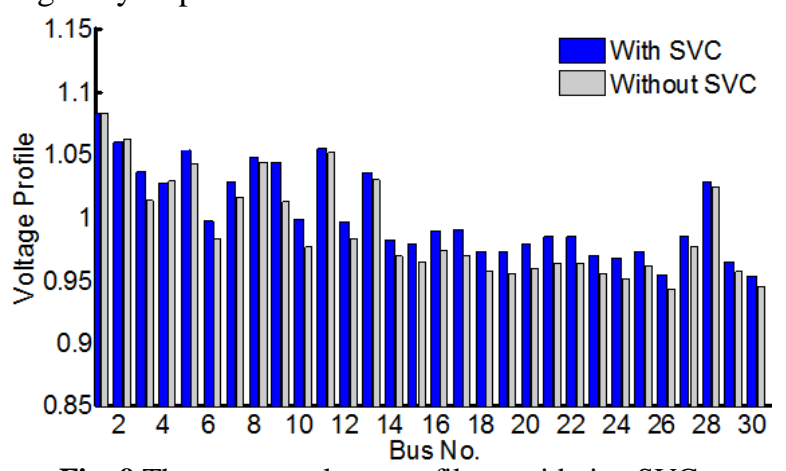

Fig. 9 The system voltage profile considering SVC

In the case of minimizing the investment cost of SVC, equation (17) must be used. The values of investment cost of SVC at all objective functions are calculated and recorded in table 2, also the optimized value of cost function of SVC is recorded.

Table 2 Results of IEEE 30 -Bus System considering SVC

\begin{tabular}{|c|c|c|c|c|}
\hline & \multicolumn{4}{|c|}{ With SVC } \\
\hline Objectives & $\begin{array}{l}\text { Fuel } \\
\text { Cost } \\
\$ / h r\end{array}$ & $\begin{array}{c}\text { Powe } \\
\text { r Loss } \\
\text { MW }\end{array}$ & $\begin{array}{c}\text { Voltage } \\
\text { Deviatio } \\
\mathrm{n} \\
\text { P.U. }\end{array}$ & $\begin{array}{l}\text { SVC } \\
\text { cost } \\
\$ / \mathrm{hr}\end{array}$ \\
\hline $\begin{array}{l}\text { Minimizin } \\
\mathrm{g} \\
\text { Total fuel } \\
\text { cost }\end{array}$ & 800.627 & 10.91 & 0.0576 & $\begin{array}{c}72.69 \\
9\end{array}$ \\
\hline $\begin{array}{l}\text { Minimizin } \\
\mathrm{g} \\
\text { Power loss } \\
\end{array}$ & $\begin{array}{c}966.15 \\
9\end{array}$ & 3.12 & 0.0995 & $\begin{array}{c}72.67 \\
8\end{array}$ \\
\hline $\begin{array}{c}\text { Minimizin } \\
\mathrm{g} \\
\text { Voltage } \\
\text { Deviation } \\
\end{array}$ & $\begin{array}{c}821.38 \\
0\end{array}$ & 5.96 & 0.0275 & $\begin{array}{c}68.29 \\
4\end{array}$ \\
\hline $\begin{array}{c}\text { Minimizin } \\
\text { g } \\
\text { FACTS } \\
\text { Cost } \\
\end{array}$ & $\begin{array}{c}819.78 \\
0\end{array}$ & 9.22 & 0.056 & 59.232 \\
\hline
\end{tabular}

\subsection{OPF using PSO considering UPFC}

The placement of the UPFC in the network must be determined and then, the setting of the control parameters of UPFC is optimized by controlling the device parameters. Locations of FACTS devices in the power system are obtained based on their performances using the static voltage stability index (SVSI), measured for each line at the same operating conditions. UPFC is installed at the weakest buses and heavily loaded areas to reduce stressed condition in the power system. SVSI technique has been applied as a tool to indicate the UPFC location into the network. When the load flow program is run, stability indices are calculated for each line one at a time for the same operating conditions. The highest
SVSI lines in the system identify the buses for the purpose of installing UPFC [17-19]. The mathematical formulation for SVSI is given as:

$$
S V S I_{j i}=\frac{2 \sqrt{\left(R_{j i}^{2}+X_{j i}^{2}\right)\left(P_{j}^{2}+Q_{j}^{2}\right)}}{\left|V_{i}^{2}-2 X_{j i} Q_{j i}-2 R_{j i} P_{j i}\right|}
$$

where, $\mathrm{i}$ is the sending end bus and $\mathrm{j}$ the receiving end bus of the line $\mathrm{i}-\mathrm{j}, \mathrm{R}_{\mathrm{ji}}$ and $\mathrm{X}_{\mathrm{ji}}$ are resistance and reactance of the line, $P_{j}$ and $Q_{j}$ are the receiving end real and reactive powers. The values of the SVSI have range between 0 and 1.1 represents the voltage instability condition while 0 , the no load condition. The value of SVSI should be kept well below 1 to ensure the power system under voltage stability condition.

Considering the SVSI approach for determining the optimal location of UPFC, it is found that highest five lines are between buses: 2-3, 1-11, 1-2, 2-13 and 28-27 respectively. These five line buses are the best placement of the UPFC.

In the case of minimizing the total fuel cost considering the UPFC, it is found that the optimal location of the UPFC at the line 2-13 (with shunt part at bus 13). Fig. 10 shows the variation of total fuel cost considering UPFC. Referring to this figure, it is evident that the fuel cost is minimized to be 763.8779 $\$ / \mathrm{hr}$. from to this value, it can be concluded that existence of the UPFC at suitable placement achieve the least value of fuel cost compared with the previous case.

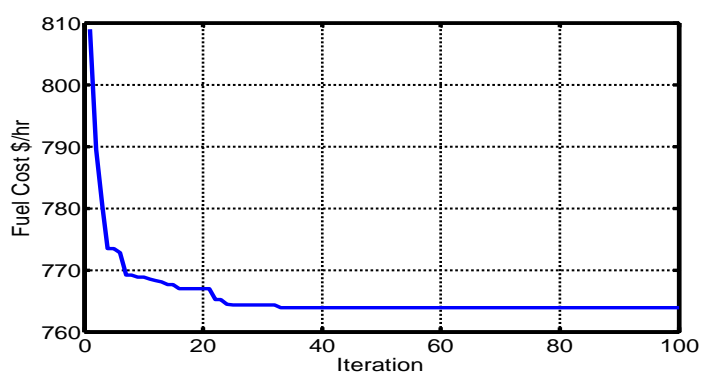

Fig. 10 Fuel Cost variation considering UPFC

To minimize the total active power losses in transmission network, the UPFC placed at the optimal location (bus 13 and bus 2). The variation of the total power loss considering the UPFC is shown in Fig. 11. Referring to this figure, it is illustrated that the total power loss is optimized to $2.81 \mathrm{MW}$, this value is more minimized compared to that case of SVC. 


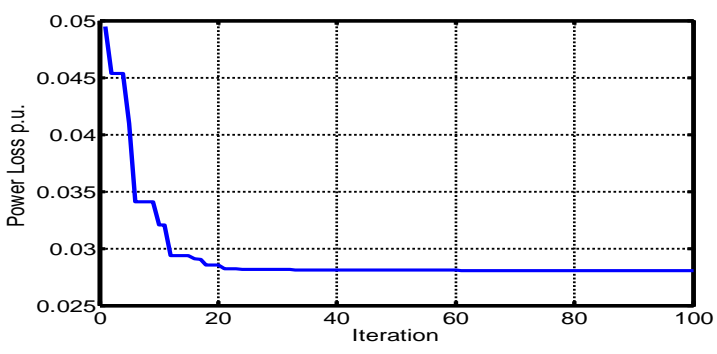

Fig. 11 The power loss variation considering UPFC

In the case of minimizing the voltage deviation, it is found that the optimal location of UPFC at line 2728. Referring to the optimization results, it is found that the summation of voltage deviation is minimized to 0.0154 P.U. It is evident that the summation of voltage deviation considering the UPFC is more minimized compared with the previous case.

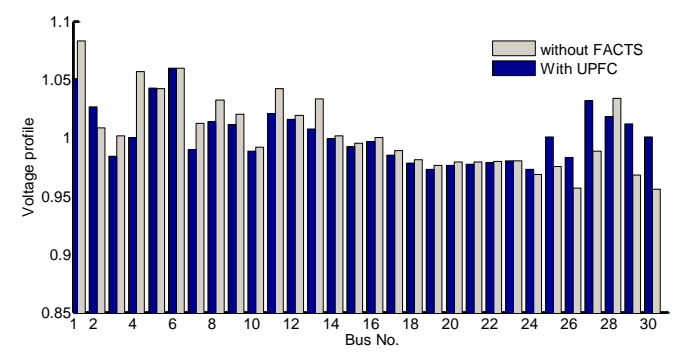

Fig. 12 System voltage profile with UPFC and without FACTS

In the case of minimizing the investment cost of UPFC, equation (18) should be used. The values of investment cost of UPFC at all objective functions are calculated and recorded in table 3 , also the optimized value of cost function of UPFC is recorded.

Table 3 Results of IEEE 30 -Bus System considering UPFC

\begin{tabular}{|c|c|c|c|c|}
\cline { 2 - 5 } \multicolumn{1}{c|}{} & \multicolumn{4}{c|}{ With UPFC } \\
\hline Objectives & $\begin{array}{c}\text { Fuel } \\
\text { Cost } \\
\$ / h r\end{array}$ & $\begin{array}{c}\text { Power } \\
\text { Loss } \\
\text { MW }\end{array}$ & $\begin{array}{c}\text { Voltage } \\
\text { Deviation } \\
\text { P.U. }\end{array}$ & $\begin{array}{c}\text { UPFC } \\
\text { cost } \\
\$ / h r\end{array}$ \\
\hline $\begin{array}{c}\text { Minimizin } \\
\mathrm{g} \\
\text { Total fuel } \\
\text { cost }\end{array}$ & $\mathbf{7 6 3 . 8 7 7}$ & 15.72 & 0.1557 & 25.935 \\
\hline $\begin{array}{c}\text { Minimizin } \\
\mathrm{g} \\
\text { Power loss }\end{array}$ & 936.000 & $\mathbf{2 . 8 1}$ & 0.8499 & 26.435 \\
\hline $\begin{array}{c}\text { Minimizin } \\
\mathrm{g} \\
\begin{array}{c}\text { Voltage } \\
\text { Deviation }\end{array}\end{array}$ & 828.326 & 12.07 & $\mathbf{0 . 0 1 5 4}$ & 25.529 \\
\hline $\begin{array}{c}\text { Minimizin } \\
\mathrm{g}\end{array}$ & 833.650 & 14.98 & 0.1076 & $\mathbf{2 2 . 9 0 4}$ \\
$\begin{array}{c}\text { FACTS } \\
\text { Cost }\end{array}$ & & & & \\
\hline
\end{tabular}

Referring to the recorded results in tables 2 and 3, the values of all objectives under study (total fuel cost, system power losses, installation cost of FACTS and voltage profile improvement) are more optimized in the case of considering UPFC.

\section{CONCOLUSION}

The optimal installation of FACTS devices plays a key role in achieving the proper functionality of these devices. However, this paper made an attempt to find out the optimal location and parameters setting of SVC and UPFC devices to minimize generation fuel cost, system power losses, installation cost of FACTS and voltage profile improvement using PSO. With the above proposed algorithm it is possible for utility to place each SVC and UPFC in transmission system such that proper power planning and operation can be achieved with minimum objectives. The optimal placement of FACTS devices should be determined for each objective function individually. The simulation results illustrate the effectiveness of the proposed UPFC with optimal settings compared with SVC in terms of reduced total fuel cost, power loss, installation cost of FACTS and voltage deviations.

\section{REFERENCES}

[1] N. R. Abdullah, I. Musirin and M. M. Othman, "Transmission Loss Minimization and UPFC Installation Cost using Evolutionary Computation for Improvement of Voltage Stability", the $14^{\text {th }}$ International Middle East Power Systems Conference (MEPCON'10), Cairo University, Egypt, Paper ID 293, December 19-21, 2010.

[2] N. K. Easwaramoorthy and R. Dhanasekaran, "Solution of Optimal Power Flow Problem Incorporating Various FACTS Devices", International Journal of Computer Applications, Volume 55, No. 4, October 2012.

[3] R. P. Behnke, et al," OPF With SVC and UPFC Modeling for Longitudinal Systems", IEEE Transactions On Power Systems, Vol. 19, No. 4, November 2004.

[4] R. Vanitha and M. Sudhakaran, "Optimal Location and Control Parameter Settings of UPFC using Differential Evolution Algorithm", International Journal of Computer Applications, Volume 31, No. 4, October 2011.

[5] M. Behshad, A. Lashkarara and A. H. Rahmani, "Optimal Location of UPFC Device Considering System Loadability, Total Fuel cost, Power losses and Cost of Installation", $24^{\text {th }}$ International Power System Conference, PSC 2009.

[6] S. A. Jumaat, I. Musirin, M. M. Othman, and H. Mokhlis, "PSO Based Technique for Loss Minimization Considering Voltage Profile and 
Cost Function", The $5^{\text {th }}$ International Power Engineering and Optimization Conference (PEOCO2011), Shah Alam, Selangor, Malaysia : 6-7 June, 2011.

[7] Kalaivani and V. Kamaraj, "Enhancement of Voltage Stability by Optimal Location of Static Var Compensator Using Genetic Algorithm and Particle Swarm Optimization", American J. of Engineering and Applied Sciences, (C) Science Publications, pp.70-77, 2012.

[8] N. G. Hingorani and L. Gyugyi, "Understanding FACTS, Concepts and Technology of Flexible AC Transmission Systems", Book, The Institute of Electrical and Electronics Engineers, Inc., New York, Feb. 2005.

[9] Sh. Udgir, S. Varshney, L. Srivastava "Optimal Placement and Sizing of SVC for Voltage Security Enhancement", International Journal of Computer Applications, Volume 32- No. 6, October 2011.

[10] S. A. Jumaat, I. Musirin and M. M. Othman, "Transmission Loss Minimization using SVC Based on Particle Swarm Optimization", IEEE Symposium on Industrial Electronics and Applications (ISIEA 2011), September 25-28, 2011.

[11] R. Sirjani, A. Mohamed and H. Shareef, "Optimal Placement and Sizing of Static Var Compensators in Power Systems Using Improved Harmony Search Algorithm", Przegląd Elektrotechniczny (Electrical Review), ISSN 0033-2097, 2011.

[12] W. M. Lin, K. H. Lu, Ch. M. Hong and Ch. Sh. $\mathrm{Tu}$, "Optimal Location of FACTS for Voltage stability using Modified Particle Swarm Optimization", International Multi-Conference of Engineers and Computer scientists, Vol. II, Hog Kong, March 14-16, 2012.
[13] S. Kamel, M. Abdel-Akher, and M.K. El-nemr, "Direct Modeling of UPFC in Newton Raphson Power Flow Analysis Based on Current Injections", the $14^{\text {th }}$ International Middle East Power Systems Conference (MEPCON'10), Cairo University, Egypt, pp. 769-774, December 19-21, 2010.

[14] R. Tiwari, K. R. Niazi and V. Gupta, "Decoupled Power Exchange Model of UPFC to Enhance Voltage Stability Margin of Power Systems", IEEE @, 2011.

[15] G. A. Morsy, R. A. Amer and E. Saad "Optimal Power Flow Control Based Shunt FACTS Devices Using PSO Algorithm", ERJ, Fac. Of Eng., Minoufiya Univ., Vol. 36, No. 3, 2013.

[16] M. Saad S. Al-ghamdi, "Multi-Objective Optimal Power Flow", Master of Science in Electrical Engineering, May 2004.

[17] K. Manoz K. Reddy, "Transmission Loss Minimization Using Advanced Unified Power Flow Controller (UPFC)", IOSR Journal of Engineering, Vol. 2(5) pp. 1049-1052, May. 2012.

[18] S. Sakthivel, D. Mary and M. Deivarajamani, "Reactive Power Planning for Voltage Stability Limit Improvement with FACTS Devices in Most Critical Contingency Condition", European Journal of Scientific Research, ISSN 1450-216X, (C) Euro Journals Publishing, Vol.66, No.3, pp. 408-420, 2011.

[19] S. Sakthivel, D. Mary and S. Ramya, "Reactive Power Optimization and Voltage Stability Limit Improvement with TCSC Device Through DE Algorithm Under Most Credible Contingency Condition" International Journal of Scientific \& Engineering Research, Volume 3, Issue 5, May2012. 